\title{
LAS TRANSFORMACIONES DEL RÉGIMEN DE INTERVENCIÓN ADMINISTRATIVA EN EL PROCEDIMIENTO DE EVALUACIÓN DE INCIDENCIA AMBIENTAL DE ACTIVIDADES. EL SUPUESTO PARTICULAR DE LA LEGISLACIÓN GALLEGA ${ }^{1}$
}

\author{
ANDREA GARRIDO JUNCAL \\ Profesora contratada interina de Derecho Administrativo \\ Universidad de Santiago de Compostela \\ andrea.garrido@usc.es
}

Recibido: 31 de marzo de 2016 / Aceptado: 3 de junio de 2016

RESUMEN: El trabajo tiene como objeto el examen de algunas de las principales cuestiones relacionadas con el nuevo procedimiento para la evaluación de incidencia ambiental de actividades, el cual se estructura, tras la aprobación de la Ley 9/2013, de 19 de diciembre, del Emprendimiento y de la Competitividad Económica de Galicia, en dos fases. En primer lugar, el interesado debe solicitar la emisión de una declaración de incidencia ambiental al órgano autonómico competente en medio ambiente, $y$, una vez obtenida esta, debe presentar una comunicación previa ante el ayuntamiento donde prevea implantar la actividad. Después de un estudio pormenorizado del articulado aplicable a esta materia, la parte final del trabajo se dedica a analizar la intervención de las entidades de certificación de conformidad municipal como mecanismo de reforzamiento de las técnicas de control ex post para garantizar que la eliminación del control previo no se traduzca en transgresiones de la normativa.

RESUM: El treball té com a objectiu l'examen d'algunes de les qüestions principals relacionades amb el nou procediment per a l'avaluació de la incidència ambiental d'activitats, el qual s'estructura, després de l'aprovació de la Llei 9/2013, de 10 de

\footnotetext{
${ }^{1}$ Este trabajo se ha elaborado en el marco del proyecto de investigación "El nuevo régimen jurídico de las Administraciones públicas y del procedimiento administrativo en el marco de la reforma administrativa" (Referencia: DER2014-51833-P).
} 
desembre, d'empreneduria i de la competitivitat econòmica de Galícia, en dues fases. En primer lloc, l'interessa ha de sol-licitat l'emissió d'una declaració d'incidència ambiental a l'òrgan autonòmic competent en matèria de medi ambient, $i$, una vegada obtinguda, ha de presentar una comunicació prèvia davant de l'ajuntament on prevegi implantar l'activitat. Després d'un estudi detallat de l'articulat aplicable a aquesta matèria, la part final del treball es dedica a analitzar la intervenció de les entitats de certificació de conformitat municipal com a mecanisme de reforçament de les tècniques de control ex post per garantir que l'eliminació del control previ no condueixi a transgressions de la normativa aplicable.

ABSTRACT: This paper examines some of the major issues related to the new environmental incidence evaluation procedure of activities, which is structured, following the adoption of the Law 9/2013, of 19 December, entrepreneurship and economic competitiveness of Galicia, in two phases. Firstly, the applicant must request the issuance of an environmental incidence declaration to the competent regional authority and, once obtained it, he must submit a prior communication to the municipality where he implements the activity. After a detailed study of the articles applicable to this matter, the final part of this paper analyzes the intervention of certification bodies as a mechanism for strengthening techniques ex post control to ensure that the elimination of previous control does not lead to violations of the rules.

PALABRAS CLAVE: Declaración de incidencia ambiental - Comunicación previa - Entidades de certificación de conformidad municipal — Licencia municipal Entidades colaboradoras de la Administración.

PARAULES CLAU: Declaració d'incidència ambiental - Comunicació prèvia Entidats de certificació de conformitat municipal — Llicència municipal - Entidats col·laboradores de l'Administració.

KEYWORDS: Environmental incidence declaration — Prior communication Certification bodies - Municipal license — Administration collaborating entities. 
Sumario. I. Consideraciones introductorias y de carácter general. II. El procedimiento para la evaluación de incidencia ambiental de actividades. 1. Primera fase: la solicitud, la tramitación y la emisión de la declaración de incidencia ambiental. 2. Segunda fase: la supresión de la licencia municipal de actividad y el régimen de comunicación previa. III. Las entidades de certificación de conformidad municipal. IV. Conclusiones para una reflexión. V. Bibliografía.

\section{CONSIDERACIONES INTRODUCTORIAS Y DE CARÁCTER GENERAL}

Desde la entrada en vigor de la Directiva 2006/123/CE del Parlamento Europeo y del Consejo, de 12 de diciembre de 2006, relativa a los servicios en el mercado interior, numerosas modificaciones normativas han sido efectuadas en los distintos ámbitos territoriales con el fin de adaptar nuestro ordenamiento jurídico al derecho de la Unión Europea y, más concretamente, a las libertades de establecimiento y de prestación de servicios que este proclama ${ }^{2}$.

Como explica J. V. GONZÁLEZ GARCÍA, el nuevo marco legal está vinculado con el principio de menor restricción en el ejercicio de las actividades de servicios. El denominado principio de menor intervención responde a una política de mayor eficacia en el ejercicio de las actividades económicas que busca favorecer su inicio con la mayor celeridad, tal como resulta de un régimen de liberalización de la mayor parte de los sectores. Conecta, directamente, con el modo de funcionar de un ente público en el contexto de la Administración electrónica; se vincula, asimismo, a una concepción extrema del mandato de simplificación administrativa; y, al eliminar los requisitos públicos, proporciona una aparente mayor competitividad de la economía, o, dicho de otro modo, es un instrumento para lograr una "economía social de mercado altamente competitiva", por citar las palabras del artículo 3.3 del Tratado de la Unión Europea ${ }^{3}$.

Las reformas legales auspiciadas por la Directiva de Servicios han reactivado un tema clásico del derecho administrativo, el de los regímenes de intervención administrativa.

\footnotetext{
${ }^{2}$ Uno de los mayores retos del derecho administrativo contemporáneo es su adecuación y la de sus instrumentos al hecho imparable de la movilidad de bienes y personas que tanto la globalización como la integración económica suponen. El derecho de la Unión Europea se ha visto frente a este dilema —un solo mercado regido por hasta veintiocho derechos nacionales distintos- y las soluciones allí adoptadas impactan fuertemente en los ordenamientos nacionales. Lo mismo, a distinta escala, se produce con la pluralidad normativa que representa el Estado autonómico español. (PADRÓS I REIG, C. y MACÍAS CASTAÑO, J. M., "Los instrumentos administrativos de garantía de la unidad de mercado", Revista de Administración Pública, núm. 194, 2014, p. 114).

3 Véase GONZÁleZ GARCÍA, J. V., "Autorizaciones, comunicaciones previas y declaraciones responsables en la transposición de la Directiva de servicios", Revista d'estudis autonòmics i federals, núm. 11, 2010, pp. 269-270.
} 
Se impone una profunda revisión del concepto de autorización y se impulsan otras formas de intervención administrativa basadas en controles realizados ex post, las declaraciones responsables y las comunicaciones previas ${ }^{4}$. Ello no significa el desmantelamiento del régimen de autorización basado en controles preventivos realizados a priori, sino su reconsideración, pues se condiciona su exigencia a la existencia de una justificación, de una razón poderosa para restringir legítimamente la libertad ${ }^{5}$.

En esa línea, el artículo 39.1 bis de la Ley 30/1992, de 26 de noviembre, de Régimen Jurídico de las Administraciones Públicas y del Procedimiento Administrativo Común (en adelante, LRJPAC) ${ }^{6}$, establece: “[...] las Administraciones Públicas que en el ejercicio de sus respectivas competencias establezcan medidas que limiten el ejercicio de derechos individuales o colectivos o exijan el cumplimiento de requisitos para el desarrollo de una actividad, deberán elegir la medida menos restrictiva, motivar su

\footnotetext{
${ }^{4}$ La declaración responsable es aquel documento que suscribe la persona física o jurídica que proyecta una actividad empresarial o profesional mediante el que declara, bajo su responsabilidad, que observa todas las exigencias impuestas por la normativa aplicable, dispone de la documentación acreditativa y se compromete a respetarla a lo largo del desarrollo de la actividad en cuestión. Por otro lado, la comunicación previa se caracteriza como aquel documento del que se sirve el prestador de una actividad de servicio para poner en conocimiento de la Administración pública sus datos identificativos y todos los demás requisitos impuestos por la legislación aplicable para el ejercicio de un derecho o el inicio de una actividad.
}

El particular que opta por ejercer un derecho sometido por el ordenamiento jurídico a simple declaración responsable ve reducidas sus obligaciones de aportación documental ante el aparato público. Se le exime de la presentación de toda la documentación legalmente requerida si declara cumplir los requisitos que la norma establece. En la comunicación previa parece existir la efectiva y previa presentación ante la Administración de los documentos que acreditan el cumplimiento de los requisitos. M. RODRÍGUEZ FONT afirma que, tal y como se configura hoy esta institución, conlleva, igual que la declaración responsable, la plena asunción de responsabilidad por los datos puestos en conocimiento al aparato público y, por lo tanto, por la actividad iniciada. (RODRÍGUEZ FONT, M., "Declaración responsable y comunicación previa: su operatividad en el ámbito local", Anuario del Gobierno Local, núm. 1, 2009, p. 266).

5 Véase FERNÁNDEZ TORRES, J. R., "Regímenes de intervención administrativa: autorización, comunicación previa y declaración responsable", Revista Catalana de Dret Públic, núm. 42, 2011, p. 19.

${ }^{6}$ El artículo 4 de la Ley 40/2015, de 1 de octubre, de Régimen Jurídico del Sector Público, prevé:

1. Las Administraciones Públicas que, en el ejercicio de sus respectivas competencias, establezcan medidas que limiten el ejercicio de derechos individuales o colectivos o exijan el cumplimiento de requisitos para el desarrollo de una actividad, deberán aplicar el principio de proporcionalidad y elegir la medida menos restrictiva, motivar su necesidad para la protección del interés público así como justificar su adecuación para lograr los fines que se persiguen, sin que en ningún caso se produzcan diferencias de trato discriminatorias. Asimismo deberán evaluar periódicamente los efectos y resultados obtenidos.

2. Las Administraciones Públicas velarán por el cumplimiento de los requisitos previstos en la legislación que resulte aplicable, para lo cual podrán, en el ámbito de sus respectivas competencias y con los límites establecidos en la legislación de protección de datos de carácter personal, comprobar, verificar, investigar e inspeccionar los hechos, actos, elementos, actividades, estimaciones y demás circunstancias que fueran necesarias. 
necesidad para la protección del interés público así como justificar su adecuación para lograr los fines que se persiguen, sin que en ningún caso se produzcan diferencias de trato discriminatorias". Podría pensarse que este camino liberalizador, desregulador y de mayor simplificación aligera la posición y responsabilidad de las administraciones públicas. Sin embargo, nada más lejos de la realidad, pues este mismo precepto contiene un segundo párrafo en el que se dispone: “[...] las Administraciones Públicas velarán por el cumplimiento de los requisitos aplicables según la legislación correspondiente, para lo cual podrán comprobar, verificar, investigar e inspeccionar los hechos, actos, elementos, actividades, estimaciones y demás circunstancias que se produzcan"7.

El objetivo esencial de este trabajo es analizar la incidencia que la generalización de la comunicación previa pueda tener en la conservación adecuada del medio ambiente, para lo cual examinaremos la Ley 9/2013, de 19 de diciembre, del Emprendimiento y de la Competitividad Económica de Galicia (en adelante, LECEG) ${ }^{8}$. Como se deduce de la exposición de motivos del citado texto legal, la puesta en marcha y la consolidación de iniciativas empresariales dependen, entre otras actuaciones, de la eliminación de las trabas burocráticas, y el elevado número de administraciones llamado a cumplir este reto recomienda que la Comunidad Autónoma establezca un régimen jurídico único del ejercicio de actividades en Galicia, de modo que la autorización se convierta en excepcional y casi residual en un futuro próximo.

No nos puede caber ninguna duda de que la voluminosa Administración local gallega ${ }^{9}$ está obligada a transponer la antedicha Directiva comunitaria, pero está claro también que la autonomía que se garantiza a esta se integra en un ordenamiento derivado, consecuencia de la consideración de los entes locales como poderes limitados que se hallan subordinados a otros ordenamientos superiores, el estatal y el autonómico, llamados a concretar y delimitar el interés local. Cabe destacar, así, lo dificultoso de la final y completa transposición de la Directiva de Servicios en el ámbito local, si bien puede decirse que un cambio de enorme envergadura ha venido de la mano de la nueva

\footnotetext{
${ }^{7}$ Véase SOCIAS CAMACHO, J. M., "El nuevo modelo de intervención Administrativa en el ámbito local”, Revista Aragonesa de Administración Pública, núm. 41-42, 2013, pp. 217-218.

${ }^{8}$ Conviene señalar que actualmente se está tramitando un reglamento que desarrolla la LECEG. Se trata del Reglamento único para la regulación integrada de actividades económicas y apertura de establecimientos, tanto de las actividades inocuas como de las actividades clasificadas y los espectáculos públicos y actividades recreativas.

${ }^{9}$ Según datos del Instituto Gallego de Estadística, 314 es el número de municipios en Galicia.
} 
redacción de los artículos 84, 84 bis y 84 ter de la Ley 7/1985, de 2 de abril, reguladora de las Bases del Régimen Local ${ }^{10}$.

La LECEG se estructura en tres títulos, tres disposiciones adicionales, dos disposiciones transitorias, dos disposiciones derogatorias y ocho disposiciones finales, más un anexo. El título I aborda el objeto de la presente Ley. El título II indica los títulos competenciales autonómicos en materia de emprendimiento; determina, a efectos de

${ }^{10}$ Para A. PALOMAR OLMEDA y R. TEROL GÓMEZ, la posibilidad de intervención de las entidades locales en las actividades de los ciudadanos contenidas en los artículos 84 y 84 bis de la LBRL podría condensarse en las cinco notas siguientes:

1. El sometimiento a licencia previa y, por consiguiente, a control preventivo de una determinada actividad es una técnica disponible para las entidades locales, aunque, cuando se trate del acceso a las actividades de servicio incluidas en la Ley 17/2009, de 23 de noviembre, sobre el libre acceso a las actividades de servicios y su ejercicio, habrá que estar a lo dispuesto en esta, pues toda ella es de carácter básico. Remisión, por lo tanto, en bloque a la señalada Ley y a los requisitos que prevé para el establecimiento de regímenes de autorización, que no son otros que los fijados por la Directiva de Servicios y que se reproducen. Asimismo, como en toda actividad de intervención de las entidades locales, se deben respetar los principios de igualdad de trato, necesidad y proporcionalidad con el objetivo que se persiga.

2. Se establece el principio general de que el ejercicio de actividades no se someterá a licencia u otro medio de control preventivo.

3. No obstante el principio general, sí que puede exigirse licencia si concurre alguna de estas dos circunstancias justificativas:

a) Una circunstancia a apreciar es que se justifique la exigencia de licencia por razones de orden público, seguridad pública o protección del medio ambiente en el lugar donde se realice la actividad, para lo cual no basten los mecanismos de la declaración responsable o la comunicación previa.

b) Una circunstancia de carácter objetivo y constatable es que el número de operadores en el mercado sea limitado por las siguientes circunstancias:

— Escasez de recursos naturales.

— Utilización del dominio público.

— Inequívocos impedimentos técnicos.

— La existencia de servicios públicos sometidos a tarifas reguladas.

4. Solo para las instalaciones o infraestructuras físicas que sean precisas para la realización de una actividad económica se establece una reserva de ley para someterlas a un régimen de autorización. Y eso, siempre que esa norma defina los requisitos esenciales de la actividad, esta sea susceptible de generar daños al medio ambiente y el entorno urbano, la seguridad o la salud pública y el patrimonio histórico, y, además, resulte proporcionada tal exigencia.

La evaluación del riesgo que se precisa debe tener en cuenta características de las instalaciones como las siguientes: a) la potencia eléctrica o energética de la instalación; b) la capacidad o aforo de la instalación; e) la contaminación acústica; d) la composición de las aguas residuales que emita la instalación y su capacidad de depuración; e) la existencia de materiales inflamables o contaminantes; y f) si las instalaciones afectan a bienes declarados integrantes del patrimonio histórico.

5. Junto al principio general de que la obtención de licencias por parte de otras administraciones no exime de la obtención de las de las entidades locales si así lo exigen las leyes sectoriales, se añade una obligación adicional para las mismas entidades locales en ese caso de concurrencia: el deber de motivar expresamente en la justificación de la necesidad de la autorización el interés general que pretende proteger y, además, que este no se encuentra ya cubierto mediante otra autorización ya existente. (El nuevo marco de ejercicio de las actividades económicas, Thomson Reuters Aranzadi, Navarra, 2014, pp. 108-109). 
este título, su ámbito de aplicación subjetivo y objetivo; y recoge un conjunto de medidas para estimular la actividad emprendedora. El título III establece la regulación integrada del ejercicio de actividades en Galicia, y suprime, con carácter general, la necesidad de obtención de licencia municipal de actividad, apertura o funcionamiento para la instalación, implantación o ejercicio de cualquier actividad económica, empresarial, profesional, industrial o comercial.

En cuanto a la prevención de los daños ambientales, es interesante analizar el capítulo II del título III de la LECEG, que comprende los artículos 31 a 38. Esta parte del articulado habilita a la Administración para controlar aquellas actividades económicas, empresariales, profesionales o comerciales que sean susceptibles de producir efectos nocivos sobre el entorno. Las técnicas de prevención ambiental citadas por el legislador autonómico son la autorización ambiental integrada ${ }^{11}$, la evaluación de impacto ambiental y la evaluación de incidencia ambiental; sin embargo, únicamente la tercera es objeto de una contemplación normativa profusa, motivo que justifica la elección del tema del presente estudio.

En aras de que la instalación, implantación o ejercicio de cualquier actividad económica, empresarial, profesional, industrial o comercial pueda realizarse en el menor tiempo posible agilizando los procedimientos de control, pero a la vez dando seguridad jurídica al interesado, a los terceros y a la propia Administración, la LECEG crea las entidades de certificación de conformidad municipal. Ante la irrupción de estos sujetos privados, se impone la necesidad de reflexionar también, en el marco de este trabajo, acerca de cómo se ve afectada la posición del particular cuando es otro particular el que ejerce funciones públicas $\mathrm{y}$, en especial, cómo se puede lograr que esta realidad no afecte a las garantías que tradicionalmente le ha ofrecido el procedimiento administrativo $^{12}$.

\footnotetext{
${ }^{11}$ El artículo 31 de la LECEG nos remite a la Ley 16/2002, de 1 julio, de Prevención y Control Integrados de la Contaminación, la cual precisa, en su artículo 2, que "esta ley será aplicable a las instalaciones de titularidad pública o privada en las que se desarrolle alguna de las actividades industriales incluidas en las categorías enumeradas en el anejo 1 y que, en su caso, alcancen los umbrales de capacidad establecidos en el mismo, con excepción de las instalaciones o partes de las mismas utilizadas para la investigación, desarrollo y experimentación de nuevos productos y procesos".

${ }^{12}$ C. PADRÓS I REIG afirma que cada vez queda más lejos la asimilación automática entre sujeto administrativo y función administrativa. En la actualidad pueden ejercer actividades de interés público (económicas o no) tanto los particulares como la Administración. La personificación jurídica que se elija no debería ser un elemento diferenciador del tratamiento legal, puesto que los fines equiparan los medios utilizados para alcanzarlos. En consonancia con lo expresado, este autor explica que, a pesar del carácter privado de las entidades colaboradoras, su actividad puede normalmente ser objeto de recurso
} 


\section{EL PROCEDIMIENTO PARA LA EVALUACIÓN DE INCIDENCIA} AMBIENTAL DE ACTIVIDADES

De acuerdo con el artículo 33.1 de la LECEG, "las actividades a las que no les resulte de aplicación la normativa sobre evaluación de impacto ambiental y que estén incluidas en el anexo de esta Ley se someterán a evaluación de incidencia ambiental". A tenor de lo expuesto, podemos entender que el ámbito de aplicación del procedimiento de evaluación de incidencia ambiental depende de la concurrencia de dos requisitos: el no sometimiento del proyecto a la Ley 21/2013, de 9 de diciembre, de Evaluación Ambiental; y la referencia a la actividad en el anexo de la LECEG. Este régimen sustituye al previsto en los artículos 13 a 19 de la Ley 1/1995, de 2 de enero, de Protección Ambiental de Galicia, que se derogan, del mismo modo que el Decreto 442/1990, de 13 de septiembre, de Evaluación del Impacto Ambiental para Galicia, y el Decreto 133/2008, de 12 de junio, por el que se regula la evaluación de incidencia ambiental $^{13}$.

El artículo 38 de la LECEG anuncia que estarán también sometidas a la previa declaración de incidencia ambiental las modificaciones sustanciales de las actividades sujetas a aquella, y detalla que se consideran sustanciales las modificaciones de las instalaciones o procesos vinculados a alguna actividad cuando se superen una serie de umbrales. La aplicación de estos resulta compleja. A título ejemplificativo, una modificación sustancial de la actividad es la que supone "un incremento superior al 50\% de la capacidad productiva de la instalación" (art. 38. 2 a)); pues bien, para el cálculo de la capacidad de las instalaciones de ganadería intensiva se ha tenido que elaborar una guía con fórmulas y ecuaciones matemáticas. Este hecho demuestra que un reto al que se enfrenta el régimen jurídico para la evaluación de incidencia ambiental de actividades en Galicia es el de proporcionar seguridad jurídica a los operadores económicos.

administrativo. (PADRÓS I REIG, C., La Administración invisible: panorama general y ejemplos prácticos de entidades colaboradoras de la Administración pública, Dykinson, Madrid, 2010, p. 426).

${ }^{13}$ La LECEG recoge un único anexo con las actividades sometidas a incidencia ambiental, de este modo se suprimen los anexos II y III del Decreto 133/2008, de 12 de junio, por el que se regula la evaluación de incidencia ambiental. Al respecto, A. PENSADO SEIJAS explica: “[...] esto se lleva a cabo por motivos de simplificación, pero que mientras podía ser defendible la supresión del anexo III, ya que las actividades inocuas vienen recogidas en la normativa de medidas urgentes de liberalización del comercio y de determinados servicios, no veo tan plausible la supresión del anexo II pues daba cabida a la consulta previa que se realizaba al órgano ambiental para el sometimiento o no de la actividad y establecía unos criterios para ello". (PENSADO SEIJAS, A., "Unificación normativa de la tramitación integral de las actividades en Galicia”, El Consultor de los Ayuntamientos, núm. 18, 2014). 
Sobre la base del artículo 33 de la LECEG, constatamos que las personas que vayan a llevar a cabo actividades sujetas a evaluación de incidencia ambiental deben, en primer lugar, solicitar la iniciación de un procedimiento para que el órgano autonómico competente en medio ambiente (en adelante, órgano ambiental) emita una declaración de incidencia ambiental y, en segundo lugar, presentar una comunicación previa ante el ayuntamiento donde se vaya a desarrollar la actividad. Por lo tanto, la principal novedad es la eliminación del trámite de la licencia de actividad a conceder por la autoridad municipal $^{14}$.

En último lugar, es merecedor de ser resaltado cabe resaltar que todas las solicitudes de licencias presentadas antes de la entrada en vigor de la LECEG (28 de diciembre de 2013) se rigen por la normativa de aplicación en el momento en que se solicitaron, sin perjuicio del cumplimiento en todo momento de las condiciones técnicas que puedan afectar a la seguridad de las personas y de los bienes o a la convivencia entre la ciudadanía, y que los interesados pueden optar entre la continuación del procedimiento o su desistimiento para acogerse a la nueva regulación.

\section{Primera fase: la solicitud, la tramitación y la emisión de la declaración de incidencia ambiental}

Respecto de la solicitud de declaración de incidencia ambiental, cabe subrayar que el artículo 34.1 de la LECEG dispone lo siguiente: “Toda persona física o jurídica que pretenda desarrollar una actividad comprendida en el anexo deberá solicitar la emisión de declaración de incidencia ambiental”. Consecuentemente, el solicitante puede ser

\footnotetext{
${ }^{14}$ Hay que insistir en que la eliminación de las licencias de actividad no supone automáticamente una desaparición de las cargas administrativas. Para conseguir el objetivo de la reducción de las cargas administrativas, es imprescindible que, a su vez, desaparezca la obligación de realizar la actividad administrativa, ya sea porque el requisito jurídico del que deriva la necesidad de practicar la actividad administrativa se deroga (por ejemplo, porque se liberalizan actividades que antes se sujetaban a autorización), ya sea porque manteniéndose el requisito se configura de tal manera que no conlleve actividad administrativa alguna para el interesado (como ocurre cuando la inscripción preceptiva en un registro administrativo, en lugar de hacerse a instancia del interesado, pasa a hacerse de oficio). De todos modos, tal y como subraya M. D. REGO BLANCO, habrá casos en los que el interés general exigirá mantener el requisito y cierta actividad burocrática para satisfacerlo. Ello supondrá mantener la carga administrativa, pero cabe aliviarla si los factores que integran su fórmula básica pasan a tener, todos o alguno, un valor menor (aunque positivo) porque: a) se reduce la documentación que hay que presentar; b) o se disponen los medios para que pueda emplearse menos tiempo en preparar y comunicar la información que hay que presentar obligatoriamente; c) o se reduce la población afectada; d) o disminuye la frecuencia con que hay que realizar la actividad administrativa. (Véase REGO BLANCO, M. D., "Las cargas administrativas: concepto y régimen jurídico para su reducción”, Simplificación del procedimiento administrativo y mejora de la regulación, GAMERO CASADO, E. (coord.), Tirant lo Blanch, Madrid, 2014, pp. 265-267).
} 
tanto una persona privada como pública, pues el legislador gallego no cierra ninguna posibilidad.

El artículo 34.2 de la LECEG explica que con estas solicitudes deberán adjuntarse un proyecto técnico redactado por técnico/a competente en la materia, de ser el caso, y una memoria descriptiva en la que se detallen los aspectos básicos relativos a la actividad, su localización y repercusiones en el ambiente, los tipos y cantidades de residuos, vertidos y emisiones generados por la actividad, y la gestión prevista para ellos, los riesgos ambientales que puedan derivarse de la actividad, la propuesta de medidas preventivas, correctoras y de autocontrol de la incidencia ambiental, las técnicas de restauración del medio afectado y el programa de seguimiento del área restaurada en los casos de desmantelamiento de las instalaciones o cese de la actividad, y los datos que, a juicio del solicitante, gozan de confidencialidad amparada en la normativa vigente. A pesar de que la norma aplicable al procedimiento no lo obliga expresamente, la página de la Consellería de Medio Ambiente, Territorio e Infraestructuras de la Xunta de Galicia informa de la necesidad de aportar también el justificante del pago de la tasa administrativa denominada "solicitud de emisión de declaración de incidencia ambiental"15.

El artículo 35.1 de la LECEG señala que "previa presentación de la solicitud, el órgano ambiental insertará la memoria presentada en la página web institucional de la consellería competente en materia de medio ambiente a fin de que las personas interesadas puedan formular observaciones o alegaciones en relación con las repercusiones ambientales de la actividad durante el plazo de quince días". Desde nuestra óptica personal, la previsión de la publicidad de la memoria se inscribe en el carácter esencial que reviste la participación ciudadana para la protección ambiental, especialmente impulsada por la Ley 27/2006, de 18 de julio, por la que se regulan los derechos de acceso a la información, de participación pública y de acceso a la justicia en materia de medio ambiente ${ }^{16}$.

Véase
15
tema/c/Avaliacion_ambiental?content=SX_Calidade_Avaliacion_Ambiental/Avaliacion_incidencia_ambi
ental/seccion.html\&std=IA_solicitude.html $>(2015,23$ de octubre $)$.
16 El Convenio de Aarhus ha tenido la importante virtualidad de poner en la primera página de la
actualidad política y administrativa los derechos de las personas en relación con la Administración
pública, en concreto los derechos a que la Administración difunda información, al acceso a la
información, a la participación pública en la política ambiental y, finalmente, a la tutela judicial. Este
convenio ha sido ratificado por el Estado español, también por la Unión Europea, y en el ámbito de esta
última se han dictado reglamentos de ejecución que obligan a sus instituciones, así como directivas que 
Sin perjuicio de la valoración positiva que nos merece esta obligación de suministrar información sin que medie una petición previa, pensamos que la redacción de la norma en este punto podría ser objeto de alguna mejora. En primer lugar, puesto que la memoria se presenta con la solicitud de declaración de incidencia ambiental, creemos que el momento temporal en el que se proyecta su difusión es incorrecto. En segundo lugar, desconocemos el motivo por el que el legislador prevé solo la difusión de la memoria y no del proyecto técnico. La razón de tal restricción puede fundamentarse en que la aportación del último no es siempre obligatoria. Advertida la posible justificación de dicha omisión, opinamos que sería recomendable publicar los dos documentos en el supuesto que ambos obraran en poder de la Administración ${ }^{17}$. En tercer lugar, nos llama la atención que el medio elegido para suministrar la información sea la página web institucional de la consellería competente en medio ambiente, en lugar de la sede electrónica. A estos efectos, recordamos que, según el artículo 10 de la Ley 11/2007, de 22 de junio, de acceso electrónico de los ciudadanos a los servicios públicos, la sede electrónica es una dirección electrónica que asegura la integridad, veracidad y actualización de la información accesible a través de esta y, por consiguiente, aporta a los ciudadanos las garantías de plena certeza y seguridad en sus relaciones con la Administración $^{18}$.

El reconocimiento de la facultad de formular alegaciones en relación con las repercusiones ambientales de la actividad a las personas interesadas, así como la posibilidad de consultar simultáneamente a las administraciones afectadas o a otras personas físicas o jurídicas, públicas o privadas, vinculadas a la protección del medio

vinculan a los Estados miembros. Las obligaciones relativas a la difusión de información ambiental se derivan, por tanto, de normas internacionales y de normas europeas conjuntamente. (LASAGABASTER HERRARTE, I., "Información administrativa y transparencia en la ordenación del territorio y el medio ambiente", Revista Vasca de Administración Pública, núm. 83, 2009, p. 199).

17 Esta idea debe ser compartida por el órgano ambiental, pues el proyecto técnico se expone en ocasiones. Véase http://www.cmati.xunta.es/informacion-publica-de-proxectos-de-incidenciaambiental?p_p_id=AIAPortlet_WAR_AIAPortlet_INSTANCE_D4wp\&p_p_lifecycle=0\&p_p_state=nor mal\&p_p_mode $=$ view\&p_p_col_id=-column-

$1 \& p \_p \_c o l \_c o u n t=1 \&$ AIAPortlet_WAR_AIAPortlet_INSTANCE_D4wp_accion=paginacion\&_AIAPo rtlet_WAR_AIAPortlet_INSTANCE_D4wp_pagina $=\overline{1}(2015,23$ de octubre $)$

${ }^{18}$ La disposición derogatoria única de la Ley 39/2015, de 1 de octubre, del Procedimiento Administrativo Común de las Administraciones Públicas, señala que queda derogada expresamente la Ley 11/2007, de 22 de junio, de acceso electrónico de los ciudadanos a los servicios públicos. Téngase en cuenta que la disposición final séptima de la Ley 39/2015 establece un plazo de dos años desde su entrada en vigor para que produzcan efectos las previsiones relativas al registro electrónico de apoderamientos, registro electrónico, punto de acceso general electrónico de la Administración y archivo único electrónico, y, por tanto, hasta ese momento se mantendrán en vigor los artículos de la Ley 11/2007 que traten sobre las materias citadas. 
ambiente constituyen otro ejemplo de inserción de reglas democráticas en los procesos decisorios (art. 35 de la LECEG). No obstante, tal y como apunta J. A. RAZQUIN LIZARRAGA, el reconocimiento de la participación pública no conlleva siempre una práctica fructífera, tanto por su configuración formalista y el déficit de mecanismos participativos adecuados como por la falta de respuesta ciudadana. De ahí que sea menester el fomento y la adecuada organización de la participación pública por las administraciones públicas y la instrumentación de técnicas participativas que favorezcan una participación efectiva más allá de su configuración meramente formal ${ }^{19}$.

El artículo 35.4 de la LECEG advierte que "si el ayuntamiento emitiera un informe de no compatibilidad del proyecto con planeamiento urbanístico, el órgano ambiental dictará resolución motivada poniendo fin al procedimiento y archivando las actuaciones". A nuestro juicio, sería muy conveniente que, antes de poner fin al procedimiento, se diera audiencia al interesado. A mayor abundamiento, subrayamos que de la lectura del artículo transcrito se deriva a sensu contrario que, si el ayuntamiento emitiera un informe de no compatibilidad del proyecto con las ordenanzas locales, el órgano ambiental podría continuar el procedimiento. Desde esta perspectiva, la potestad reglamentaria, como instrumento para canalizar la intervención de los entes locales sobre la protección del medio ambiente, parece que se devalúa.

La declaración de incidencia ambiental deberá ser emitida en el plazo máximo de dos meses desde la presentación de la solicitud, y establecerá, en su caso, las medidas preventivas, correctoras o de restauración que han de observarse en la implantación, desarrollo y cese de la actividad (art. 36.1 de la LECEG). Si el plazo venciera sin haberse notificado resolución expresa, el silencio tendrá efecto estimatorio, por lo que la persona solicitante quedará vinculada por las medidas preventivas, correctoras y de restauración recogidas en la memoria presentada con la solicitud (art. 36.2 de la LECEG $)^{20}$. Desde nuestro punto de vista, sería adecuado que se detallara también que,

\footnotetext{
${ }^{19}$ Véase RAZQUIN LIZARRAGA, J. A., "Los derechos ambientales de información, participación y justicia y su régimen en la Comunidad Autónoma Vasca", Revista Vasca de Administración Pública, núm. 87-88, 2010, pp. 885-886.

${ }^{20}$ En contra del silencio positivo se posiciona B. LOZANO CUTANDA, quien defiende: “[...] cuando hay un interés público relevante, no puede dejarse al albur de la Administración otorgar por silencio un permiso o licencia para una actividad que pueda afectar a ese interés, pensemos en el urbanismo o el medio ambiente, pues tal licencia únicamente podrá luego revisarse de oficio por la propia Administración si concurre una causa de nulidad de pleno derecho (e incluso es posible que bajo esta técnica se escuden quienes, sabedores de que se trata de una actuación ilícita, la quieran otorgar por razones espurias pero sin pronunciarse de forma expresa y mucho más comprometida)". (LOZANO CUTANDA, B., "Últimos cambios en las técnicas de intervención administrativa: el difícil equilibrio
} 
si la Administración incumpliera la obligación de resolver, la persona solicitante quedaría vinculada a las medidas de autocontrol y al programa de seguimiento del área restaurada en los casos de desmantelamiento de las instalaciones o cese de la actividad. En suma, convendría que se declarara que el solicitante queda sujeto a todas las obligaciones de dar, hacer o no hacer incluidas en su memoria en los casos de resolución presunta en sentido favorable. Como colofón, destacamos la importancia de que el órgano ambiental se pronuncie expresamente y, en particular, decida acerca de la prestación de una fianza que cubra la reparación de los posibles daños y el posible coste de la restauración cuando lo estime oportuno.

El artículo 28 de la LECEG expone que la declaración de incidencia ambiental tiene efectos jurídicos vinculantes para la autoridad municipal. Ante la posible duda de si tal declaración vulnera la autonomía local constitucionalmente garantizada, resulta adecuado comentar la Sentencia núm. 37/2014, de 11 de marzo, del Tribunal Constitucional, por la que se desestima el conflicto en defensa de la autonomía local promovido por el Ayuntamiento de Gomecello contra la Ley de Castilla y León 6/2005, de 26 de mayo, de declaración de proyecto regional para la instalación de un centro de tratamiento de residuos urbanos para la provincia de Salamanca, en el término municipal de Gomecello.

La oposición de la entidad local se fundamentaba en que había quedado desprovisto de sus competencias en materia de urbanismo, medio ambiente y autofinanciación, mientras que la defensa de la Comunidad Autónoma de Castilla y León se apoyaba en que la Ley impugnada se había aprobado en el ejercicio de las competencias atribuidas por la legislación autonómica y en que la participación del municipio se había respetado al haber participado este en el procedimiento administrativo previo. Tras un repaso de la doctrina relativa al alcance de la autonomía local, el Tribunal Constitucional concluye que, aunque una materia se encuentre entre los asuntos de interés de los municipios, no supone una intromisión ilegítima en la autonomía local el que, concurriendo razones que lo justifiquen, el legislador garantice la participación o intervención del municipio por otros medios (fundamento de derecho séptimo). Extrapolando esta afirmación al presente caso, cabe anotar señalar que la expedición de la declaración de incidencia

entre la liberalización y la seguridad jurídica", CASADO CASADO, L., FUENTES I GASÓ J. R. y GIFREU I FONT, J. (dirs.), Prestación de servicios, administraciones públicas y derecho administrativo: especial referencia al derecho ambiental, Tirant lo Blanch, Valencia, 2013, p. 157) 
ambiental está precedida por una serie de actos de trámite (trámite de información pública, por ejemplo) que permiten al municipio expresar su voluntad y criterio en relación con el ejercicio de competencias que le asisten, de ahí que se descarte que la exención de licencias ambientales $\mathrm{u}$ otros actos administrativos similares por parte de las entidades locales comporte una conculcación de la autonomía local.

\section{Segunda fase: la supresión de la licencia municipal de actividad y el régimen de comunicación previa}

Una vez obtenida la declaración de incidencia ambiental, la persona interesada presentará una comunicación previa ante el ayuntamiento donde prevea implantar la actividad. Con la comunicación previa se aportará, además de la documentación anunciada en el artículo 24 de la LECEG, la copia del proyecto de la obra o actividad firmada por técnico/a responsable, la declaración de incidencia ambiental y la certificación del/la técnico/a o los/as técnicos/as facultativos/as que autoricen el proyecto de que este cumple con la normativa técnica de aplicación. En nuestra opinión, la exigencia a la persona interesada de adjuntar la declaración de incidencia ambiental podría suprimirse, puesto que el artículo 36.3 de la LECEG impone la obligación al órgano ambiental de notificarla al ayuntamiento y el artículo 35 de la LRJPAC $^{21}$ reconoce el derecho de los ciudadanos "a no presentar documentos no exigidos por las normas aplicables al procedimiento de que se trate, o que ya se encuentren en poder de la Administración actuante" (apartado f).

Paradigma de lo expuesto es la Sentencia de 17 marzo de 2010 de la Sala de lo Contencioso-Administrativo, Sección 4. ${ }^{\mathrm{a}}$, del Tribunal Supremo, que anuló el artículo 4 de la Ordenanza sobre evaluación ambiental de actividades del Ayuntamiento de Madrid aprobada por el Pleno de la Corporación en la sesión ordinaria celebrada el 27 de enero de 2005. En el fundamento de derecho segundo del mencionado pronunciamiento judicial se explica que, en un contexto en el que se tiende a la simplificación de trámites administrativos, el hecho de que se exija la aportación de un documento que ya obra en poder del ayuntamiento contraviene lo dispuesto en el

\footnotetext{
${ }^{21}$ El artículo 53.1 de la Ley 39/2015, de 1 de octubre, del Procedimiento Administrativo Común de las Administraciones Públicas, dispone que los interesados en un procedimiento administrativo tienen el derecho "a no presentar datos y documentos no exigidos por las normas aplicables al procedimiento de que se trate, que ya se encuentren en poder de las Administraciones Públicas o que hayan sido elaborados por éstas" (apartado d).
} 
artículo 35 de la LRJPAC. El Tribunal Supremo considera además que es necesario partir de la base de que el principio de eficacia o de eficiencia exigible a toda Administración pública (art. 103 de la Constitución) comprende también los principios de celeridad y economía, encontrándose la Administración pública, en todo caso, al servicio de los ciudadanos. Así las cosas, abogamos por la supresión del apartado b) del artículo 28 de la LECEG al entender que el ayuntamiento no puede imponer requisitos innecesarios a los administrados. Si el despliegue territorial de funciones provoca que la Comunidad Autónoma no notifique, o notifique con retraso, la declaración de incidencia ambiental al ayuntamiento donde se prevé implantar la actividad, estamos ante un problema de coordinación entre entes públicos y de ello no puede responsabilizarse, de ningún modo, al ciudadano.

La comunicación previa presentada cumpliendo todos los requisitos constituye un acto jurídico particular que, de acuerdo con la Ley, habilita para el inicio de la actividad o la apertura del establecimiento y, en su caso, para el inicio de la obra o instalación (art. 25.1 de la LECEG). Al respecto, conviene puntualizar que, si bien la comunicación previa es calificada como "acto jurídico particular" conforme a la LECEG, el artículo 71 bis de la LRJPAC ${ }^{22}$ se limita a denominarla "documento". Esta discrepancia nos conduce al debate de la naturaleza jurídica de las comunicaciones previas y las declaraciones responsables. J. A. RAZQUIN LIZARRAGA asegura que, desde la perspectiva subjetiva, son actos de sujetos privados y no provienen de las administraciones públicas. No son, por lo tanto, actos administrativos, por lo que no puede aplicárseles el régimen jurídico propio de estos (validez, eficacia, revisión, etc.). Este autor afirma que "la declaración responsable y la comunicación previa son actos jurídicos de carácter privado, que habilitan para el ejercicio de un derecho o actividad, con eficacia propia, externa y jurídico-pública, sin precisar de ulterior confirmación administrativa. Sustituyen, a la postre, a los tradicionales actos administrativos autorizatorios. Son, en fin, actos jurídicos privados desarrollados bajo la responsabilidad de su emisor y sujetos a un control administrativo posterior; esto es, una

\footnotetext{
${ }^{22}$ El artículo 69 de la Ley 39/2015, de 1 de octubre, del Procedimiento Administrativo Común de las Administraciones Públicas, cataloga la declaración responsable y la comunicación previa como "documentos".
} 
autocertificación",23.

El artículo 37 de la LECEG dispone que, sin perjuicio de las competencias atribuidas a la Administración autonómica, corresponde al ayuntamiento la vigilancia y el seguimiento del cumplimiento de las condiciones establecidas en la declaración de incidencia ambiental y que, de conformidad con la Ley 1/1995, de 2 de enero, de Protección Ambiental de Galicia, se establecerán sanciones administrativas, penales o civiles para quienes incumplan las obligaciones ${ }^{24}$. Tal y como manifiestan J. R. FUENTES I GASÓ y L. CASADO CASADO, resulta imprescindible concretizar el régimen de control ex post y reforzar los medios personales, materiales y financieros asignados a esta función. Es indispensable que se determine adecuadamente cómo va a realizarse tanto el control puramente formal de la documentación técnica y administrativa que se presenta en el correspondiente registro para iniciar una determinada actividad como el control material relativo a su desarrollo, mediante actuaciones de comprobación e inspección ${ }^{25}$. Precisamente en esta línea, la disposición adicional tercera de la LECEG proclama: "En el plazo de un año desde la aprobación de la presente ley todas las Administraciones en que el medio de control de inicio de actividades se realice por comunicaciones previas o declaraciones responsables deberán regular las medidas y procedimientos de control operativo, habilitar los cuerpos de inspección pertinentes, diseñar planes de inspección periódica y establecer las tasas que, en su caso, procedan por estos controles".

\footnotetext{
${ }^{23}$ Véase RAZQUIN LIZARRAGA, J. A., "De la intervención administrativa previa al control a posteriori: la reforma del procedimiento administrativo común a consecuencia de la directiva de servicios", Revista Aranzadi Doctrinal, núm. 2, 2010.

${ }^{24}$ El problema que puede plantearse es el de divergencias en torno al cumplimiento o no de los requisitos entre la Administración pública y el particular. En estos casos, sería conveniente prever la posibilidad de que el prestador de servicios tuviera la oportunidad de legalizar la actividad en aquellos casos en que ello resultara posible, y si no lo hiciera o no pudiera materialmente realizarlo, se le diera la oportunidad de cesar en la actividad si no ha ocasionado ningún daño a terceros o a intereses públicos relevantes, sin que se le hubiera de exigir responsabilidad. En este sentido, la responsabilidad sancionadora debería erigirse como la ultima ratio dirigida a incumplimientos contumaces o cuando conste una voluntad inequívoca de pretender vulnerar el ordenamiento jurídico. (AGUADO I CUDOLÀ, V., "La libertad de establecimiento de los prestadores de servicios: autorización, declaración responsable, comunicación previa y silencio positivo", AGUADO I CUDOLÀ, V. y NOGUERA DE LA MUELA, B. (dirs.), Impacto de la Directiva de Servicios en las Administraciones Públicas: aspectos generales y sectoriales, Barcelona, Atelier, 2012, p. 86).

${ }^{25}$ Véase FUENTES I GASÓ, J. R. y CASADO CASADO, L., "Administración local y medio ambiente: supresión de licencias de actividad y avance de los regímenes de comunicación y declaración responsable", LÓPEZ RAMÓN, F. (coord.), Observatorio de políticas ambientales, 2013, pp. 438-439.
} 


\section{LAS ENTIDADES DE CERTIFICACIÓN DE CONFORMIDAD MUNICIPAL}

La supresión de licencias de apertura, previas a la instalación y al inicio de la actividad, requiere un reforzamiento de las técnicas de control ex post para garantizar que la eliminación del control previo no se traduzca en transgresiones de la normativa aplicable. Consciente de ello, la LECEG ha apostado por la intervención en este campo de las entidades de certificación de conformidad municipal (en adelante, Eccom). Sin embargo, las disposiciones jurídicas relativas a estas figuras han sido objeto de discrepancias competenciales entre la Administración general del Estado y la Xunta de Galicia, diferencias que han sido solventadas con la adopción de un acuerdo remitido al Tribunal Constitucional.

A tenor de lo dispuesto en la Resolución de 7 de julio de 2014, de la Secretaría General de Coordinación Autonómica y Local, por la que se publica el Acuerdo de la Comisión Bilateral de Cooperación Administración General del Estado-Comunidad Autónoma de Galicia en relación con la Ley 9/2013, de 19 de diciembre, del Emprendimiento y de la Competitividad Económica de Galicia ${ }^{26}$, se constata que las diferencias afloran respecto de la redacción de los artículos 23 y siguientes, el artículo 33.2, apartados a), b) y c), el 41, apartado f), el 47 y el 48.1 de la LECEG.

De acuerdo con el artículo 47 de la LECEG, las Eccom son organismos dotados de plena capacidad de obrar que, después de haber sido autorizados por la consellería competente en materia de seguridad industrial, pueden desarrollar, en todo el territorio de la Comunidad Autónoma de Galicia, actuaciones de certificación, verificación, inspección y control de la conformidad de las instalaciones, establecimientos y actividades con la normativa de aplicación en el ámbito municipal ${ }^{27}$.

\footnotetext{
${ }^{26}$ Publicado en el BOE núm. 179, de 24 de julio de 2014, páginas 59083 a 59084.

${ }^{27}$ La exposición de motivos de la LECEG justifica el sometimiento de las Eccom a una autorización administrativa del siguiente modo: "Habida cuenta de que el cometido de las entidades de certificación de la conformidad ha de llevarse a cabo con un elevado nivel de calidad y de profesionalidad, que deben regirse conforme a los principios de imparcialidad, confidencialidad e independencia, que su labor tendrá efectos administrativos para los ciudadanos y que su funcionamiento y actos estarán bajo el control de la Administración, está justificado que por razones de interés general su actividad esté sometida a autorización administrativa previa en las condiciones contempladas en el artículo 5 de la Ley 17/2009, de 23 de noviembre, estableciéndose para ello requisitos objetivos que garanticen la no discriminación y la proporcionalidad". El artículo 48 de la LECEG impone a las Eccom también su inscripción en un registro y la suscripción de una póliza que cubra los riesgos de su responsabilidad, sin que esta limite dicha responsabilidad. Ahondando en la incidencia de la normativa de servicios en la ordenación de las actividades e instalaciones de gestión de residuos, PERNAS GARCÍA hace hincapié en el hecho de que la
} 
En los últimos tiempos, numerosas empresas y sujetos privados colaboran de forma activa con la Administración en ámbitos que, por su complejidad técnica o por la simple imposibilidad de las administraciones de seguir asumiendo funciones, se decide que pasen a estar en manos de los particulares. Los ejemplos en estos momentos son muchos y variados: inspección de vehículos, inspección de barcos de recreo, inspecciones técnicas de edificios, empresas certificadoras en materia de medio ambiente e incluso actividades totalmente ajenas al ámbito industrial y medioambiental, como ocurre con la certificación de la idoneidad de las familias en materia de adopción, etc. ${ }^{28}$

Para compensar este trasvase de funciones públicas hacia sujetos privados, la Administración ha de intensificar su labor reguladora $\mathrm{y}$, a la vez, someterlos a un estricto control. A los poderes públicos les corresponde la regulación de la actividad de estos sujetos privados, el establecimiento del parámetro normativo de su actividad, la habilitación del ejercicio de la actividad y la inspección de su ejercicio, sin olvidar que estos sujetos caen bajo el ámbito de la específica potestad sancionadora. La intensidad de este control, en sentido amplio, debe ser correlativa a la importancia, sectorial y funcional, de la actividad desarrollada por estos sujetos; solo así es posible combinar la flexibilidad y la descarga de tareas que representa para la Administración con la garantía de la legalidad y el interés público ${ }^{29}$. Por lo demás, la potestad de supervisión reservada a las instancias públicas es un claro indicador de que el fenómeno aquí estudiado no supone un nuevo supuesto de privatización de funciones públicas ${ }^{30}$.

El recurso a las entidades colaboradoras debe siempre respetar un límite: no empeorar la posición del ciudadano. Dicho de otra manera, la decisión normativa de que el ejercicio de una función pública no sea realizado total y directamente por la Administración titular, sino que cuente con la colaboración de una entidad privada, no puede suponer nunca un perjuicio para el ciudadano. Por ejemplo, no puede suponer una disminución

obligación de que los gestores de residuos se inscriban en un registro autonómico no es compatible con el artículo 9.1 de la "Ley Paraguas". A partir de las reflexiones del citado autor, ponemos de manifiesto los problemas de encuadre jurídico del artículo 48 de la LECEG. (PERNAS GARCÍA, J. J., "Técnicas preventivas de protección ambiental y normativa de servicios: Análisis particularizado de la evaluación de impacto ambiental y de la ordenación administrativa de la gestión de residuos", Revista Catalana de Dret Ambiental, vol. 1, núm. 2, 2010, p. 31).

28 Véase CUETO PÉREZ, M., Procedimiento administrativo, sujetos privados y funciones públicas, Thomson Civitas, Navarra, 2008, p. 161.

29 Véase BETANCOR RODRÍGUEZ, A., "Control, inspección y órdenes. Comunicación previa y declaración responsable”, Derecho ambiental, La Ley, Madrid, 2014, p. 392.

${ }^{30}$ Véase CANALS I AMETLLER, D., El ejercicio por particulares de funciones de autoridad. Control, inspección y certificación, Comares, Granada, 2003, p. 331. 
de sus derechos ni de sus garantías ${ }^{31}$. En esta dirección, la LECEG declara que las Eccom se regirán por los principios de imparcialidad, confidencialidad e independencia $(\text { art. 47.2) })^{32}$ y que su labor estará sometida al control de la Administración local y de la consellería competente en materia de seguridad industrial (art. 50). Estas previsiones nos parecen correctas, aunque insuficientes, pues, como señala A. NOGUEIRA LÓPEZ, no se regulan en modo alguno, por ejemplo, los conflictos de intereses que se puedan presentar en el ejercicio de su actividad por la existencia de lazos económicos o de otro tipo con las empresas que son objeto de los controles de las Eccom ${ }^{33}$.

En el ejercicio de sus funciones, las Eccom emiten documentos (actas, informes, dictámenes, certificados, etc.) de cuyo contenido responden únicamente ellas frente a las administraciones, sustituyendo la responsabilidad de los demás interesados, es decir, de las personas titulares de la instalación, actividad, establecimiento u obra (art. 47.3 de la LECEG) ${ }^{34}$. Teniendo en cuenta que el artículo 49.2 del mismo texto legal señala que los citados documentos "podrán ser asumidos por las Administraciones sin perjuicio de sus competencias", pensamos que el sistema de responsabilidad exclusivo pretendido originariamente por el legislador puede convertirse, en la práctica, en un sistema de responsabilidad compartido entre las Eccom y las administraciones. La sospecha anterior la apoyamos en el propio significado del término "asumir", que, según la Real Academia de la Lengua Española, quiere decir "atraer a sí, tomar para sí" (primera acepción) y "hacerse cargo, responsabilizarse de algo, aceptarlo" (segunda acepción). En relación con esta cuestión, cabe señalar que convendría también analizar la posición en la que quedaría el ayuntamiento en el caso de que emitiera criterios interpretativos acerca de la aplicación de determinada normativa municipal y estos informes técnicos y

\footnotetext{
31 Véase GALÁN GALÁN, A. y PRIETO ROMERO, C., "El ejercicio de funciones públicas por entidades privadas colaboradoras de la Administración”, Anuario de Derecho Municipal, núm. 2, 2008, p. 67.

${ }^{32}$ Para la efectividad de los principios de imparcialidad e independencia, el artículo 49.3 de la LECEG propone: "En el ejercicio de sus funciones, las Eccom y el personal dependiente de ellas desarrollará sus funciones con independencia, estableciéndose reglamentariamente las disposiciones en materia de incompatibilidades".

33 NOGUEIRA LÓPEZ, A., "La Administración comprobadora: defensa de los intereses generales y desarrollo de las garantías de los ciudadanos”, ARIAS MARTÍNEZ, M. A. y ALMEIDA CERREDA, M. (coords.) y NOGUEIRA LÓPEZ, A. (dir.), La termita Bolkestein: mercado único vs. derechos ciudadanos, 2012, Civitas, Madrid, p. 118.

${ }^{34}$ Se plantea la duda acerca de cuál es el régimen de responsabilidad al que están sometidas las entidades privadas colaboradoras: el régimen de responsabilidad civil o bien el régimen de responsabilidad administrativa. La doctrina discrepa sobre esta cuestión. Para conocer los argumentos que pueden esgrimirse en fundamento de ambas tesis, nos remitimos a GALÁN GALÁN y PRIETO ROMERO, "El ejercicio..." cit., pp. 98-99.
} 
jurídicos fueran respetados por las Ecccom en sus actuaciones ${ }^{35}$. A partir de lo dispuesto en la Ley $26 / 2010$, de 3 de agosto, de régimen jurídico y de procedimiento de las administraciones públicas de Cataluña, D. CANALS I AMETLLER resalta que la Ley catalana tampoco prevé nada respecto de la imputación de los daños a la Administración pública titular de las funciones ejercidas por las entidades colaboradoras, públicas o privadas. De todas formas, esa falta de regulación no puede ser óbice, desde la óptica de esta autora, para que la casuística nos conduzca hasta casos en los cuales sea exigible a la Administración competente algún tipo de responsabilidad por el ejercicio dañino de las funciones que le competen, principalmente por las garantías formales y régimen de supervisión administrativa que regula esta ley catalana ${ }^{36}$.

En la problemática referente relativa a la identificación del responsable del contenido del documento elaborado por la Eccom y presentado ante la Administración, no podemos olvidarnos del ciudadano. En concreto, resultaría interesante preguntarse qué sucedería si la persona titular de la instalación, actividad, establecimiento u obra realizase alguna modificación o alteración respecto de las condiciones recogidas en el documento. Desde nuestro punto de vista, sería adecuado que, en el supuesto descrito, la responsabilidad de la Eccom quizá se aminorara, pero nunca se anulara. De todos modos, y a pesar de lo afirmado, habría que analizar con carácter previo la relación entre las personas que soliciten la realización de la función de certificación de conformidad municipal y las Eccom. En este sentido, L. CASADO CASADO, J. R. FUENTES I GASÓ, J. JARIA I MANZANO y A. PALLARÈS SERRANO coinciden en lo siguiente:

[...] hay que definir el tipo de relación que une a las entidades colaboradoras y los particulares, así como los derechos y obligaciones de ambas partes. En particular, hay que establecer previsiones específicas en relación con el régimen tarifario aplicable. Es evidente que las entidades colaboradoras podrán recibir una contraprestación económica por los servicios realizados, pero la normativa debe fijar cómo se determinarán las tarifas aplicables. Las opciones posibles son múltiples, en función del grado de intervención administrativa que se aplique, y

\footnotetext{
${ }^{35}$ Ello exigiría examinar previamente tres aspectos: los títulos que permiten imputar la responsabilidad al ayuntamiento, el tipo de responsabilidad en que incurre $y$, sobre todo, la articulación entre esta responsabilidad administrativa y la responsabilidad de la Eccom.

${ }^{36}$ CANALS I AMETLLER, D., "Las entidades colaboradoras de las Administraciones públicas catalanas: rasgos definitorios, actuación y régimen de intervención administrativa", TORNOS MAS, J. (coord.), Comentarios a la Ley 26/2010, de 3 de agosto, de régimen jurídico y de procedimiento de las administraciones públicas de Cataluña, Iustel, Madrid, 2012, p. 609.
} 
pueden ir desde un sistema tarifario sometido a la previa aprobación administrativa a un sistema de mayor libertad en el que las propias entidades colaboradoras fijen las tarifas correspondientes (aunque, en este caso, sería recomendable exigir, como ya hacen algunas regulaciones autonómicas y estatales, la notificación previa a la Administración y que sean de conocimiento público). Asimismo, hay que prever qué tipo de actuaciones pueden llevar a cabo las entidades colaboradoras en caso de impago por parte de sus clientes de las tarifas aplicables ${ }^{37}$.

Tras una lectura de las disposiciones reguladoras de las Eccom, surgen otros dos interrogantes: ¿aquellos organismos que cumplan los requisitos establecidos por el legislador gallego podrán actuar fuera de la Comunidad Autónoma de Galicia? y ¿los organismos legalmente establecidos en cualquier lugar del territorio nacional tendrán plena capacidad para realizar en el territorio de la Comunidad Autónoma de Galicia las funciones propias de las Eccom? La respuesta a las dos preguntas planteadas debe ser sí y su fundamentación se recoge en la Ley 20/2013, de 9 de diciembre, de garantía de la unidad de mercado (en adelante, LGUM).

Con la finalidad de "establecer las disposiciones necesarias para hacer efectiva la unidad de mercado en todo el territorio nacional" (art. 1 de la LGUM), se enuncian una serie de principios generales de la actividad económica dirigidos a servir de guía a los operadores jurídicos en la interpretación y aplicación de las normas de liberalización y unificación del mercado ${ }^{38}$. Entre ellos, conviene señalar el "principio de eficacia de las actuaciones de las autoridades competentes en todo el territorio nacional", el cual supone que "los actos, disposiciones y medios de intervención de las autoridades competentes relacionados con el libre acceso y ejercicio de la actividad económica tendrán eficacia en todo el territorio nacional" ${ }^{\text {"39 }}$. De acuerdo con este principio, desde el momento en que un operador económico esté legalmente establecido en un lugar del territorio español podrá ejercer su actividad económica en todo el territorio, mediante establecimiento físico o sin él, siempre que cumpla los requisitos de acceso a la actividad del lugar de origen, incluso cuando la actividad económica no esté sometida a

\footnotetext{
${ }^{37}$ Véase CASADO CASADO, L., FUENTES I GASÓ, J. R., JARIA I MANZANO, J. y PALLARÈS SERRANO, A., La externalización de las funciones de control e inspección en materia de protección del medio ambiente, Atelier, Barcelona, 2010, p. 186.

${ }^{38}$ De todos modos, tal y como precisa B. LOZANO CUTANDA, "la mayoría de estos principios no hacen sino reiterar y concretar para los operadores económicos algunos de los ya contenidos en la LRJPAC". (LOZANO CUTANDA, B., "Ley 20/2013, de garantía de la unidad de mercado: las diez reformas clave", Revista CESCO de Derecho de Consumo, núm. 9, 2014, p. 1).

${ }^{39}$ Este principio se desarrolla de forma específica en el capítulo V, artículos 19 y 20.
} 
requisitos en dicho lugar (art. 19.1 de la LGUM) ${ }^{40}$. Así que si el lugar de origen del operador económico es, por ejemplo, el País Vasco, en la medida en que cumpla las normas de esa comunidad autónoma, ese operador podrá prestar servicios en otra comunidad autónoma. Se dice que la eficacia nacional de las normas infraestatales, en especial, autonómicas, comporta el equivalente interno a los principios europeos del reconocimiento mutuo y del país de origen ${ }^{41}$.

La aplicación de lo explicado con anterioridad tiene, sin embargo, una excepción. Tal y como reza señala el artículo 20.4 de la LGUM, "el principio de eficacia en todo el territorio nacional no se aplicará en caso de autorizaciones, declaraciones responsables y comunicaciones vinculadas a una concreta instalación o infraestructura física. No obstante, cuando el operador esté legalmente establecido en otro lugar del territorio, las autorizaciones o declaraciones responsables no podrán contemplar requisitos que no estén ligados específicamente a la instalación o infraestructura. El principio de eficacia en todo el territorio nacional tampoco se aplicará a los actos administrativos relacionados con la ocupación de un determinado dominio público o cuando el número de operadores económicos en un lugar del territorio sea limitado en función de la existencia de servicios públicos sometidos a tarifas reguladas". De este modo, el principio de eficacia se aplicará fundamentalmente en todo aquello que esté vinculado a la licencia de actividad, mientras que no se aplicará en aquello vinculado a las licencias de construcción o de apertura ${ }^{42}$.

Por último, la introducción en nuestro ordenamiento jurídico del principio de eficacia en los términos en que se lleva a cabo por la LGUM es criticable por condicionar el ejercicio de las competencias de las comunidades autónomas, cuya normativa tendrá una eficacia limitada al poder verse desplazada por aquella que trae bajo el brazo el operador económico que decide actuar en esta comunidad autónoma o ente local como

\footnotetext{
40 En concordancia con lo expuesto, el artículo 19.3 de la LGUM precisa: "Cuando conforme a la normativa del lugar de destino se exijan requisitos, cualificaciones, controles previos o garantías a los operadores económicos o a los bienes, distintos de los exigidos u obtenidos al amparo de la normativa del lugar de origen, la autoridad de destino asumirá la plena validez de estos últimos, aunque difieran en su alcance o cuantía. Asimismo, el libre ejercicio operará incluso cuando en la normativa del lugar de origen no se exija requisito, control, cualificación o garantía alguno".

${ }^{41}$ Véase REBOLLO PUIG, M., "El Estado Autonómico tras la Ley de Garantía de la Unidad de Mercado y sus principios de necesidad y eficacia nacional", Revista Andaluza de Administración Pública, núm. 91, 2015.

${ }^{42}$ Véase TORNOS MAS, J., "La ley 20/2013, de 9 de diciembre, de garantía de la unidad de mercado. En particular, el principio de eficacia", Revista d'estudis autonòmics i federals, núm. 19, 2014, p. 159.
} 
territorio de destino ${ }^{43}$. Además, la política pública estatal a favor de la unidad de mercado puede ser una solución ineficaz, puesto que las administraciones tratarán de imponer su propia normativa, aunque sea a costa de una supresión indiscriminada de $\operatorname{cargas}^{44}$.

Por otro lado, al margen del título jurídico habilitante jurídicamente idóneo para atribuir a las Eccom el ejercicio de funciones públicas, resulta pertinente reparar en que esta modalidad de colaboración implica una intersección de lo público y lo privado que no puede ser acordada libremente por la Administración. Puesto que el tenor del artículo 12 de la LRJPAC pone de manifiesto que la competencia es irrenunciable, el principio de legalidad debe ser de plena aplicación al traslado de funciones públicas a organizaciones privadas $^{45}$. De todos modos, el cumplimiento de la mencionada reserva de ley puede objetarse teniendo en cuenta que una parte importante de la regulación no se va a recoger en una norma legal, sino en el Proyecto de Decreto por el que se aprueba el Reglamento único para la regulación integrada de actividades económicas y apertura de establecimientos, pendiente de aprobación en estos momentos ${ }^{46}$.

\section{CONCLUSIONES PARA UNA REFLEXIÓN}

La intervención de los poderes públicos imponiendo para imponer límites y condiciones a la actividad de los ciudadanos para asegurar una utilización racional de los recursos

\footnotetext{
${ }^{43}$ M. J. ALONSO MAS pone de relieve que "la LGUM busca conseguir la unidad de mercado mediante instrumentos menos incisivos que la uniformización normativa, pero paradójicamente, el resultado puede ser, a la postre, más gravoso, al imponerse en unos territorios la aplicación de normas que proceden de otros". (ALONSO MAS, M. J., "La eficacia de los títulos habilitantes en todo el territorio nacional y la aplicación de la regla de lugar de origen", ALONSO MAS, M. J. (dir.), El nuevo marco jurídico de la unidad de mercado: comentario a la Ley de garantía de la unidad de mercado, La Ley, Madrid, 2014, p. 341).

${ }^{44}$ En palabras de J. GIFREU I FONT, "a los ordenamientos jurídicos autonómicos no les va a quedar otra salida que entrar en una feroz competencia con el fin de ofrecer una producción jurídica más atractiva, y no necesariamente de mayor calidad regulatoria, a los ojos de los operadores económicos, que los convenza de los beneficios de establecerse en su territorio". (GIFREU I FONT, J., "La impronta de la Directiva de servicios y de la normativa de transposición interna estatal en las técnicas interventoras urbanísticas: Parada y fonda: la Ley de garantía de la unidad de mercado", Revista Vasca de Administración Pública, núm. 98, 2014, p. 205).

${ }^{45}$ Véase CANALS I AMETLLER, D., "El ejercicio de funciones públicas por entidades privadas colaboradoras de la Administración", GALÁN GALÁN, A. y PRIETO ROMERO, C. (dirs.), El ejercicio de funciones públicas por entidades privadas colaboradoras de la Administración, Huygens, Madrid, 2010, pp. 42-43. tramitacion/pendente-de-aprobacion/-/nt/0039/proyecto-decreto-por-que-aprueba-reglamento-unico-pararegulacion-integrada-actividades $>$.
} 
encuentra respaldo constitucional en los artículos 45.2 y 128. Las técnicas de ordenación y limitación previstas por el legislador para la protección del medio ambiente son muy variadas. Por su relación temporal con el ejercicio de los derechos o actividades en los que inciden, pueden ser previas a dicho ejercicio (autorizaciones, registro, etc.), simultáneas o concurrentes con este (actividad de inspección, de verificación, etc.), o bien consistir en una actuación posterior (de coacción o de sanción frente a los incumplimientos de sanciones) ${ }^{47}$.

El medio más idóneo para hacer efectivo el principio de precaución, característico en el derecho ambiental, es la autorización, puesto que con esta el ejercicio de las actividades económicas, empresariales, profesionales y comerciales se condiciona a la comprobación previa de su adecuación al ordenamiento jurídico ${ }^{48}$. Por imperativo de las normas de transposición de la Directiva de Servicios, primero, y la LGUM, después, se ha promovido una sustitución de los sistemas de autorización por fórmulas de control $a$ posteriori con una incidencia escasa en el ámbito de la protección ambiental, ya que "la protección del medio ambiente y del entorno urbano" constituye una de las "razones imperiosas de interés general" que permiten excepcionalmente mantener el régimen de autorización $^{49}$.

Como se ha constatado en el presente trabajo, el proceso de liberalización de actividades ha conducido a que se exija una comunicación previa, y no una licencia, para la instalación, implantación o ejercicio de cualquier actividad económica, empresarial profesional, industrial o comercial en la Comunidad Autónoma de Galicia. Ahora bien, interesa subrayar que la LECEG no permite presentar esta comunicación previa hasta que se obtenga la declaración de incidencia ambiental. Teniendo en cuenta el gran volumen de documentación que se adjunta con la solicitud del interesado, su exposición

\footnotetext{
${ }^{47}$ Véase LOZANO CUTANDA, B. (dir.), Tratado de Derecho Ambiental, CEF, Madrid, 2014, p. 396.

${ }^{48}$ E. ARANA GARCÍA y J. F. GRANADOS RODRÍGUEZ recalcan, sin embargo, que "el valor de la protección ambiental, incluso con el carácter preventivo que exige el Derecho comunitario, no se ve comprometido en ningún momento eliminándose, simplemente, trabas y obstáculos innecesarios para una más libre prestación de servicios y de establecimiento en nuestro país". Por otro lado, estos autores insisten en que "tampoco esta intervención previa — con tediosos procedimientos en materia ambientalha garantizado la correcta implantación y funcionamiento de las actividades, puesto que no son pocos los casos en nuestras ciudades de actividades clasificadas abiertas al público sin título habilitante o con flagrantes incumplimientos de medidas correctoras y de la normativa aplicable". (ARANA GARCÍA, E. y GRANADOS RODRÍGUEZ, J. F., "La desaparición de las licencias en las actividades clasificadas incluidas en el ámbito de la directiva de servicios: el supuesto particular de la legislación ambiental andaluza", Revista General de Derecho Administrativo, núm. 25, 2010, pp. 25-26).

${ }^{49}$ Véase el considerando 59 de la Directiva de Servicios y el artículo 17 de la LGUM.
} 
pública o la posibilidad de formular alegaciones respecto de su contenido, podríamos pensar que el proyecto es objeto de una fiscalización suficiente y que, en consecuencia, la eliminación de la comunicación previa y el consiguiente avance del régimen de comunicación previa resultan aconsejables. Esta percepción positiva puede tenerse también porque el legislador introduce prescripciones dirigidas a fortalecer el reconocimiento de las funciones de control de la Administración. Sin embargo, a nuestro juicio, es necesario ser cautos por dos motivos. En primer lugar, porque, aunque este fenómeno solo afecta a las actividades de menor impacto ambiental, son las que generan una mayor contestación vecinal y no se incluyen garantías procedimentales para los denunciantes. En segundo lugar, destacamos la tendencia del sector público consistente en reclamar seguridad jurídica a las entidades privadas al requerir que la documentación que acompañe la solicitud de la declaración de incidencia ambiental sea redactada por un técnico competente en la materia (art. 34 de la LECEG) y al apostar por la intervención, en este campo, de las Eccom.

Finalmente, después de la aprobación de la LECEG, consideramos que cabe cuestionarse la utilidad de la vigencia de la Ley 1/1995, de 2 de enero, de Protección Ambiental de Galicia. A nuestro criterio, una derogación de este texto legal estaría justificada por dos razones: se trata de una norma que cuenta con innumerables declaraciones programáticas de objetivos y principios vacíos de contenido; y su regulación no se adapta ni a la experiencia adquirida durante estos años ni tampoco a las últimas novedades legislativas dictadas a fin de que todos los ciudadanos disfrutemos de un medio ambiente adecuado.

\section{BIBLIOGRAFÍA}

AGUADO I CUDOLÀ, V., "La libertad de establecimiento de los prestadores de servicios: autorización, declaración responsable, comunicación previa y silencio positivo", AGUADO I CUDOLÀ, V. y NOGUERA DE LA MUELA, B. (dirs.), Impacto de la Directiva de Servicios en las Administraciones Públicas: aspectos generales y sectoriales, Barcelona, Atelier, 2012.

ALONSO MAS, M. J., "La eficacia de los títulos habilitantes en todo el territorio nacional y la aplicación de la regla de lugar de origen", ALONSO MAS, M. J. (dir.), El nuevo marco jurídico de la unidad de mercado: comentario a la Ley de garantía de la 
unidad de mercado, La Ley, Madrid, 2014.

ARANA GARCÍA, E. y GRANADOS RODRÍGUEZ, J. F., "La desaparición de las licencias en las actividades clasificadas incluidas en el ámbito de la Directiva de servicios: el supuesto particular de la legislación ambiental andaluza", Revista General de Derecho Administrativo, núm. 25, 2010.

BETANCOR RODRÍGUEZ, A., "Control, inspección y órdenes. Comunicación previa y declaración responsable", Derecho ambiental, La Ley, Madrid, 2014.

CANALS I AMETLLER, D., "El ejercicio de funciones públicas por entidades privadas colaboradoras de la Administración”, GALÁN GALÁN, A. y PRIETO ROMERO, C. (dirs.), El ejercicio de funciones públicas por entidades privadas colaboradoras de la Administración, Huygens, Madrid, 2010.

CANALS I AMETLLER, D., "Las entidades colaboradoras de las Administraciones públicas catalanas: rasgos definitorios, actuación y régimen de intervención administrativa", TORNOS MAS, J. (coord.), Comentarios a la Ley 26/2010, de 3 de agosto, de régimen jurídico y de procedimiento de las administraciones públicas de Cataluña, Iustel, Madrid, 2012.

CANALS I AMETLLER, D., El ejercicio por particulares de funciones de autoridad (control, inspección y certificación), Comares, Granada, 2003.

CASADO CASADO, L., "Inspección ambiental y liberalización de servicios y actividades económicas", SANZ LARRUGA, F.J., GARCÍA PÉREZ, M. y PERNAS GARCÍA, J. J. (dirs.), Libre mercado y protección ambiental. Intervención y orientación ambiental de las actividades económicas, Instituto Nacional de la Administración Pública, Madrid, 2013.

CASADO CASADO, L., FUENTES I GASÓ, J. R., JARIA I MANZANO, J. y PALLARÈS SERRANO, A., La externalización de las funciones de control $e$ inspección en materia de protección del medio ambiente, Atelier, Barcelona, 2010.

CUETO PÉREZ, M., Procedimiento administrativo, sujetos privados y funciones públicas, Thomson Civitas, Navarra, 2008.

FUENTES I GASÓ, J. R. y CASADO CASADO, L., “Administración local y medio ambiente. Supresión de licencias de actividad y avance de los regímenes de comunicación y declaración responsable”, LÓPEZ RAMÓN, F. (coord.), Observatorio 
de politicas ambientales 2013, Thomson-Aranzadi, Pamplona, 2013.

GALÁN GALÁN, A. y PRIETO ROMERO, C., "El ejercicio de funciones públicas por entidades privadas colaboradoras de la Administración", Anuario de Derecho Municipal, núm. 2, 2008.

GIFREU I FONT, J., "La impronta de la Directiva de servicios y de la normativa de transposición interna estatal en las técnicas interventoras urbanísticas: Parada y fonda: la Ley de garantía de la unidad de mercado", Revista Vasca de Administración Pública, núm. 98, 2014.

GONZÁLEZ GARCÍA, J. V., “Autorizaciones, comunicaciones previas y declaraciones responsables en la transposición de la Directiva de servicios", Revista d'estudis autonòmics i federals, núm. 11, 2010.

LASAGABASTER HERRARTE, I., "Información administrativa y transparencia en la ordenación del territorio y el medio ambiente", Revista Vasca de Administración Pública, núm. 83, 2009.

LOZANO CUTANDA, B. (dir.), Tratado de Derecho Ambiental, CEF, Madrid, 2014.

LOZANO CUTANDA, B., "Ley 20/2013, de garantía de la unidad de mercado: las diez reformas clave", Revista CESCO de Derecho de Consumo, núm. 9, 2014.

LOZANO CUTANDA, B., "Últimos cambios en las técnicas de intervención administrativa: el difícil equilibrio entre la liberalización y la seguridad jurídica", CASADO CASADO, L., FUENTES I GASÓ, J. R. y GIFREU I FONT, J. (dirs.), Prestación de servicios, administraciones públicas y derecho administrativo: especial referencia al derecho ambiental, Tirant lo Blanch, Valencia, 2013.

NOGUEIRA LÓPEZ, A., "La Administración comprobadora: defensa de los intereses generales y desarrollo de las garantías de los ciudadanos”, ARIAS MARTÍNEZ, M. A. y ALMEIDA CERREDA, M. (coords.) y NOGUEIRA LÓPEZ, A. (dir.), La termita Bolkestein: mercado único vs. derechos ciudadanos, 2012, Civitas, Madrid.

PADRÓS I REIG, C. y MACÍAS CASTAÑO, J. M., "Los instrumentos administrativos de garantía de la unidad de mercado", Revista de Administración Pública, núm. 194, 2014. 
PADRÓS I REIG, C., La Administración invisible: panorama general y ejemplos prácticos de entidades colaboradoras de la Administración pública, Dykinson, Madrid, 2010.

PALOMAR OLMEDA, A. y TEROL GÓMEZ, R. (dirs.), El nuevo marco de ejercicio de las actividades económicas, Thomson Reuters Aranzadi, Navarra, 2014.

PENSADO SEIJAS, A., "Unificación normativa de la tramitación integral de las actividades en Galicia”, El Consultor de los Ayuntamientos, núm. 18, 2014.

PERNAS GARCÍA, J. J., “Técnicas preventivas de protección ambiental y normativa de servicios: Análisis particularizado de la evaluación de impacto ambiental y de la ordenación administrativa de la gestión de residuos", Revista Catalana de Dret Ambiental, vol. 1, núm. 2, 2010.

RAZQUIN LIZARRAGA, J. A., "De la intervención administrativa previa al control a posteriori: la reforma del procedimiento administrativo común a consecuencia de la Directiva de servicios", Revista Aranzadi Doctrinal, núm. 2, 2010.

RAZQUIN LIZARRAGA, J. A., "Los derechos ambientales de información, participación y justicia y su régimen en la Comunidad Autónoma Vasca", Revista Vasca de Administración Pública, núm. 87-88, 2010.

REBOLLO PUIG, M., "El Estado Autonómico tras la Ley de Garantía de la Unidad de Mercado y sus principios de necesidad y eficacia nacional", Revista Andaluza de Administración Pública, núm. 91, 2015.

REGO BLANCO, M. D., "Las cargas administrativas: concepto y régimen jurídico para su reducción", GAMERO CASADO, E. (coord.), Simplificación del procedimiento administrativo y mejora de la regulación, Tirant lo Blanch, Madrid, 2014.

RODRÍGUEZ FONT, M., "Declaración responsable y comunicación previa: su operatividad en el ámbito local”, Anuario del Gobierno Local, núm. 1, 2009.

SOCIAS CAMACHO, J. M., "El nuevo modelo de intervención Administrativa en el ámbito local”, Revista Aragonesa de Administración Pública, núm. 41-42, 2013.

TORNOS MAS, J., "La ley 20/2013, de 9 de diciembre, de garantía de la unidad de mercado. En particular, el principio de eficacia", Revista d'estudis autonòmics $i$ federals, núm. 19, 2014. 
